\title{
Research on Business Model Innovation of Smart City Construction
}

\author{
Yuxia Li \\ Xi'an Eurasia University, Xi'an, Shaanxi, 710065, China
}

Keywords: Wisdom; city; business model

\begin{abstract}
The smart city we are talking about is to integrate all the links involved in the urban development process into the information system in the past, and to effectively manage it, and use the information and communication technology to make our city intelligent. The development is guaranteed. In the current era of continuous development of information technology, smart cities have certain inevitability in the process of construction. The current development of smart cities has also brought very serious challenges to the development of urban business. But to be able to create a very good living environment for the residents of our cities, so that they can ensure that the city develops in a harmonious and stable direction, it is necessary to integrate the development of the current smart city to enable it to innovate business development model. Based on this, this paper will provide research and analysis on the innovation of business model in the process of smart city construction.
\end{abstract}

\section{Introduction}

In the era of continuous development of information technology, it can be said that the craze for smart city construction is constantly rising. According to incomplete statistical results, the number of smart cities in China has reached more than 100 target cities. It is still improving. The connection between smart city construction and information technology and communication technology is also closer. However, in view of the actual situation analysis at the current stage of development, China's smart city construction is still at a stage of exploration, and the business model of smart city construction still remains. It has not been formed, so this situation has also had a certain impact on the function of smart cities. Naturally, to a certain extent, it has restricted the development of smart cities in a stable and sustainable direction. However, under the current wave of construction and development of smart cities, if we want to enable smart cities to maintain a sustainable and stable development trend, we need to establish a commercial development model that is consistent with smart cities. Only real construction has been built. A business development model that is consistent with a smart city can provide the needs of people's lives in the current city, thus promoting the current city's continued development in a harmonious and stable direction.

\section{Overview of smart cities}

Smart cities currently use information technology such as technology to provide comprehensive management of relevant information in key urban operational systems, so that they can meet the current and sustainable development needs of urban development. And because the current social development environment is very fast, the construction of smart cities has become a general trend of maintaining sustained and stable development, which plays a very important role in the development of China's cities. First of all, the construction of smart cities can be said to be a way to guarantee the stability of the city. In the current era of rapid economic development, more and more people have entered the city to live. This development trend has led to the continuous growth of the urban population, and this situation also gives us national urban construction and urban management. It has brought great troubles and difficulties, and urban conflicts have intensified. Smart cities are the strategic choice for building a smart city as a whole and improving China's overall competitiveness. The carrier of a smart city is technology. With the construction of a smart city, it will also promote the rise of the current generation of information technology in strategic 
development, and with the current development of smart cities, the development of various industries in China will be guaranteed. The overall competitiveness of national enterprises is guaranteed.

\section{The problems of the business model of smart city construction}

The construction of smart cities mainly takes some technical methods such as information technology and communication technology as the basis for development. It can be said that this is a certain technical work. If you want to quickly promote the sustainable development of the current smart city, you need to have one. As a support, the operating entities that match the development needs of smart cities are not only required to have very strong service capabilities, but also require very specialized management capabilities. However, in view of the current business model analysis of the construction and development of smart cities in our country, the main operators are still relatively scarce. The current commercial operations of the city are mainly multinational enterprises. The number of local enterprises can be said to be very small. Local enterprises are not in a state of management or service, and this situation is very restrictive for the future development of smart cities.

The development concept of China's smart city is also relatively short. The current work is still in its infancy, so the related work is not very mature, but as the city of the current city alone, the products and services that it requires are still relatively simple. It does not stand in the market and consumers' own needs to innovate products and services, and this situation naturally cannot satisfy the needs of consumers. In addition, in the process of continuous construction of the current smart city, the wisdom should be used in the service is still in a continuous exploration stage, many companies are not willing to go to large-scale production during the production of products, so that the product is blocked The function and price and performance are not acceptable to consumers. In particular, the underlying consumers cannot form a relatively large-scale market development demand, so they cannot meet the current profit demand of enterprises, but if they cannot To maintain profitability, companies will naturally reduce their investment in production. Such a situation also causes the city to shrink and cannot guarantee the city's sustained and stable development.

\section{The principle of building a business model for smart city construction}

In the process of building a smart city, the distribution of benefits can be said to be the main problem that must be faced in the process of building a smart city business model. For the stakeholders concerned, if the distribution of interests is not very fair, then it will naturally It has an impact on the construction of urban commercial forms. Therefore, when designing a business model, it is necessary to adhere to the development principle of cooperation and win-win. It is not only to mobilize the enthusiasm of various aspects of work, but also to consider the distribution of interests in many different aspects. Ensure the effectiveness of the distribution of benefits, so that it can maintain a cooperative and win-win development model between stakeholders or companies.

As the current business entity, in the process of establishing a business model of a smart city, if the business entity cannot maintain a stable profit, then naturally it will slowly disappear in the market, and serious will make wisdom The development of the urban commercial market has shrunk. Therefore, in the business model, we must maintain a stable profit, and it also needs a very broad market space and a stable profit point, so that it can better penetrate the business activities of the enterprise.

In the past, in the process of stable development of urban business, the government's ability to intervene in business is very large. This situation makes the current developmental role of the enterprise unable to obtain reasonable and effective play. In the process of establishing a smart city business model, it is necessary to properly decentralize the rights to the enterprise, and it is necessary to show the government's own functions and roles as much as possible, and at the same time improve the previous government monopolization of the market. Enterprises can play the role 
of their own market players and mobilize their enthusiasm for development.

\section{The smart city business model innovation construction strategy}

First of all, if the government wants to realize the construction of a smart city, it must strengthen its understanding and understanding of relevant knowledge, fully grasp the knowledge of some Internet and Internet of Things, and effectively use the development model of the Internet and the Internet of Things to develop these models. The foundation is to promote the management of smart cities and actively establish a business model that matches the development of smart cities. Second, the government needs to decentralize its functions appropriately, fully exert its role as a market entity, and at the same time participate in the channels. There is a need to actively promote multi-agent participation, such as the promotion of cooperation between local and foreign countries, between government and enterprises, between capital and technology, projects and current market development; in the actual form of operation, it is necessary to promote diversity The form of development, the confirmation of different forms of cooperation, the overall adjustment of local development goals, the focus on external development and internal management. Moreover, the government needs to actively carry out work with corporate development and smart promotion. It enables it to provide a very effective information consulting service for market development entities and consumers, thus building a variety of platforms to promote the current smart city to maintain faster and more stable development.

First of all, if companies want sustainable development, they will not be able to help the government. Therefore, it is necessary to change the traditional forms of government projects and other companies to grab projects, and to achieve cooperation with government departments. And then use the funds to jointly develop and share resources for the project, in this way to activate the development of the commercial market and promote the development of the urban economy in a better direction; secondly, if the enterprise wants to be able to stand on the current market Therefore, when it is established, it is necessary to actively carry out the service work of the relevant products in the early, middle and late stages according to its own development strategy and related development strategies, so that consumers can truly feel the service belt. Convenience and benefits. Moreover, it is necessary to carry out price adjustments in a timely manner, so that the products launched by the enterprises can become products that truly serve consumers, so that consumers can truly make up and use them, thereby stabilizing the position of enterprises in the market main body and promoting enterprises. While maintaining better and faster development, we will expand the development market and promote the rapid construction and development of smart cities.

In the process of building a smart city, an important content is the establishment of the city's public infrastructure. If you want to build a business model that is consistent with a smart city, you still need to increase the input of the department to make the city The establishment of public infrastructure can support the development of the business model, and make every effort to bring together the diverse information resources of the city, thus rapidly promoting the effective integration and sharing between physical technology facilities and information facilities, making the city more The application of a domain smart environment can be guaranteed and improved. In addition, it is necessary to strengthen urban management, take the people-oriented development concept as the development principle, and actively link the government with enterprises and the masses so that the three parties can share the same process in the construction of smart cities. Only in this way can the city's commercial economy last forever, strengthen the city's overall competitiveness and the brand effect of the company.

\section{Conclusion}

The development and construction of a smart city has become an inevitable outcome of the current development of modern society. At present, China has put into action from theoretical research in the construction of a smart city. When building the current smart city, we It is not only necessary to understand the achievements of the development of smart cities, but also the need to 
recognize very clearly the problems and challenges that may arise in the process of building smart cities. However, in spite of this, in order to maintain a healthy and stable development of the city, we must actively promote the development and construction of smart cities, find a business model for supporting development in the process of building a smart city, and truly bring the wisdom of the government to a new type of society. The wisdom of enterprise development is integrated, and the service people are the foundation of development. They go hand in hand and strive for the goal of building a smart city with speed.

\section{References}

[1] Liu Shanghai. Research on the Business Model of Smart City Construction and Operation in China [J]. Future and Development, 2013, 08:24-29.

[2] Ruo Chonghui, Li Mingchao, Zhu Wenjing. Research on Business Model Innovation of Smart City Construction [J]. Zhejiang Academic Journal, 2015, 06:216-221.

[3] Xu Xiaomin, Zhou Hongcheng. Analysis of the construction and operation mode of smart city [A]. Sichuan Institute of Communications. Proceedings of the 2015 Annual Conference of Sichuan Communication Society [C]. Sichuan Communication Society (Sichuan) Institute of Communications), 2015: 3.

[4] Han Tianqi. Research on the construction and operation mode of smart city [D]. Beijing University of Posts and Telecommunications, 2013.

[5] Xu Xiaomin, Zhou Hongcheng. Analysis of the Construction and Operation Mode of Smart City [J]. Communication and Information Technology, 2014, 01:41-42. 